\title{
Pregnenolone Sulfate Activates NMDA Receptor Channels
}

\author{
E. ADAMUSOVÁ ${ }^{1}$, O. CAIS ${ }^{1}$, V. VYKLICKÝ ${ }^{1}$, E. KUDOVÁ ${ }^{2}$, H. CHODOUNSKÁ ${ }^{2}$, \\ M. HORÁK ${ }^{1}$, L. VYKLICKÝ Jr ${ }^{1}$
}

${ }^{1}$ Institute of Physiology, Academy of Sciences of the Czech Republic, Prague, Czech Republic,

${ }^{2}$ Institute of Organic Chemistry and Biochemistry, Academy of Sciences of the Czech Republic, Prague, Czech Republic

Received April 22, 2013

Accepted October 3, 2013

\begin{abstract}
Summary
Pregnenolone sulfate (PS), an endogenously occurring neurosteroid, has been shown to modulate the activity of several neurotransmitter-gated channels, including the NMDA receptor (NMDAR). NMDARs are glutamate-gated ion channels involved in excitatory synaptic transmission, synaptic plasticity, and excitotoxicity. In this study, we analyzed the effects of PS on calcium signaling in cultured hippocampal neurons and HEK293 cells expressing NMDAR. The cells were loaded with the $\mathrm{Ca}^{2+}$ sensor Fura-2. In agreement with previous electrophysiological experiments, PS potentiated the increases in intracellular $\mathrm{Ca}^{2+}$ induced by an exogenous application of glutamate; however, PS also increased intracellular $\mathrm{Ca}^{2+}$ in the absence of exogenous NMDA agonist. The agonist-independent effect of PS was induced in all neurons studied and in HEK293 cells expressing GluN1/GluN2A-B receptors in a neurosteroid-specific manner. We conclude that PS is an endogenous NMDA agonist that activates the GluN1/GluN2A-B receptors.
\end{abstract}

\section{Key words}

Neurosteroids • $\mathrm{N}$-methyl-D-aspartate receptor • Pregnenolone sulfate $\bullet$ Calcium imaging $\bullet$ Recombinant receptors

\section{Corresponding author}

Ladislav Vyklický Jr., Institute of Physiology AS CR, v.v.i., Videnska 1083, 14220 Prague 4, Czech Republic.

Fax: (420) 24106 2488. E-mail: vyklicky@biomed.cas.cz

NMDA receptors (NMDARs), a subtype of ionotropic glutamate receptors, are involved in synaptic transmission and plasticity (Citri and Malenka 2008). These receptors are positively and negatively modulated by neurosteroids. Pregnanolone sulfate $(3 \alpha 5 \beta S)$ is an endogenous neurosteroid that has a use-dependent effect though voltage-independent inhibitory action on NMDARs (Park-Chung et al. 1994, Abdrachmanova et al. 2001, Petrovic et al. 2005). On the other hand, pregnenolone sulfate (PS), a structurally similar neurosteroid, allosterically potentiates responses mediated by NMDARs (Wu et al. 1991, Bowlby 1993, Park-Chung et al. 1994). Its action is dependent on the receptor subunit composition and receptor state; i.e., upon receptor activation, the PS affinity is decreased $\sim 50$-fold (disuse-dependent action) (Horak et al. 2004). At $\mathrm{GABA}_{\mathrm{A}}$ receptors, three mechanisms have been described for neurosteroid modulation at physiologically relevant concentrations: potentiation (Zhu and Vicini 1997, Stell et al. 2003), direct receptor activation (Majewska et al. 1986), and inhibition (Majewska and Schwartz 1987, Wang et al. 2002). Even though the binding site(s) by which these effects are mediated has not yet been firmly identified, pharmacological, functional, and molecular studies indicate multiple binding sites (Hosie et al. 2007).

All experiments were carried out in accordance with the European Communities Council Directive (86/609/EEC) and with the approval of the Institutional Animal Care and Use Committee. Primary dissociated hippocampal cultures were prepared from 1- to 2-day-old postnatal rats. Animals were decapitated, and the hippocampi were dissected. Trypsin digestion, followed by mechanical dissociation, was used to prepare cell suspension. Single cells were plated at a density of 500,000 cells $/ \mathrm{cm}^{2}$ on $31-\mathrm{mm}$ or $12-\mathrm{mm}$ polylysine-coated 
glass cover slips. Neuronal cultures were maintained in Neurobasal $^{\mathrm{TM}}$-A (Invitrogen, Carlsbad, CA) medium supplemented with glutamine $(0.5 \mathrm{mM})$ and B-27 SerumFree Supplement (Invitrogen).

HEK293 cells (American Type Culture Collection, ATTC No. CRL1573, Rockville, MD) were cultured in Opti-MEM ${ }^{\circledR}$ I (Invitrogen) with $5 \%$ fetal bovine serum at $37^{\circ} \mathrm{C}$ and transfected with GluN1/ GluN2/GFP plasmids as described previously (Cais et al. 2008). Equal amounts $(0.3 \mu \mathrm{g})$ of cDNAs coding for GluN1, GluN2, and GFP (green fluorescent protein) (pQBI 25, Takara, Japan) were mixed with $0.9 \mu \mathrm{l}$ of Matra-A Reagent (IBA, Göttingen, Germany) and added to confluent HEK293 cells on a 24-well plate. After trypsinization, the cells were resuspended in Opti-MEM ${ }^{\circledR}$ I containing $1 \%$ fetal bovine serum supplemented with $20 \mathrm{mM} \quad \mathrm{MgCl}_{2}, \quad 1 \mathrm{mM} \quad$ D,L-2-amino-5phosphonopentanoic acid, and $3 \mathrm{mM}$ kynurenic acid and plated on 30-mm polylysine-coated glass cover slips. The following gene-encoding NMDAR subunits were used: GluN1-1a (GluN1; GenBank accession no. U08261) (Hollmann et al. 1993), GluN2A (GenBank accession no. D13211) (Ishii et al. 1993), GluN2B (GenBank accession no. M91562) (Monyer et al. 1992). NMDAR subunits were identified with the nomenclature recently recommended by IUPHAR (Collingridge et al. 2009).

The calcium-sensitive fluorescent dye fura-2AM (Molecular Probes, Eugene, OR) was used to determine transient alterations in intracellular calcium concentration $\left(\left[\mathrm{Ca}^{2+}\right]_{\mathrm{i}}\right.$ ). Cells (HEK293 cells $24-48$ hours after the end of transfection or primary hippocampal neurons cultured for 5-8 days) were incubated in $5 \mu \mathrm{M}$ fura-2AM for $60 \mathrm{~min}$ at $37^{\circ} \mathrm{C}$ in the presence of extracellular solution (ECS) containing (in $\mathrm{mM}$ ) $160 \mathrm{NaCl}, 2.5 \mathrm{KCl}$, 10 HEPES, 10 glucose, and $2 \mathrm{CaCl}_{2}$ (pH-adjusted to 7.3 with $\mathrm{NaOH}$ ) supplemented with $1 \mathrm{mM} \mathrm{MgCl}_{2}, 0.02 \%$ pluronic acid, and $25 \mu \mathrm{M}$ probenecid. Cells were then washed three times with $\mathrm{Mg}^{2+}$-containing ECS and incubated for an additional $30 \mathrm{~min}$ before imaging. Fura2 was excited alternately at 340 and $380 \mathrm{~nm}$ and an image of the emission from each excitation wavelength was collected using fluorescence imaging system $\mathrm{Cell}^{\wedge} \mathrm{R}$ (Olympus) consisting of an inverted microscope Olympus IX 81 equipped with a cooled CCD camera Hamamatsu Orca-ER (Hamamatsu Photonics K.K., Shizuoka, Japan) and Polychromator V (TILL Photonic, Munich, Germany). The following filters were used: excitation filter SP410, emission filter LP440, and dichroic mirror DCLP410 (Olympus). All cells within the field of view were analyzed for each experiment. The average number of cells imaged per field of view was $15 \pm 3$. The cells in the experimental chamber were perfused with $\mathrm{Mg}^{2+}$ containing ECS at the rate of $0.1 \mathrm{ml} / \mathrm{min}$ at room temperature. Glycine $(20 \mu \mathrm{M})$, an NMDAR co-agonist, was routinely used. TTX $(0.5 \mu \mathrm{M})$ was used in experiments on cultured hippocampal neurons. 20oxopregn-5-en-3 $\beta$-yl sulfate (PS; pregnenolone sulfate) solutions were made from freshly prepared $30 \mathrm{mM}$ stock in dimethyl sulfoxide (DMSO). The same concentration of DMSO (1\%) was maintained in the test and control extracellular solutions.

Fluorescence intensity was measured in cell bodies and expressed as fluorescence ratio $F_{340 / 380}(t)=$ $F_{340} / F_{380}$, where $t$ is time and $F_{340}$ and $F_{380}$ are the fluorescence intensities measured at 340 and $380 \mathrm{~nm}$, respectively. Relative change in the fluorescence $(\Delta F)$ induced by drug treatment was calculated from $\Delta F=$ $F_{340 / 380}$ (test) $-F_{340 / 380}$ (control), where $F_{340 / 380}$ (test) is the maximal fluorescence intensity achieved during test solution application (usually 1-2 $\mathrm{min}$ ) and $F_{340 / 380}$ (control) is the fluorescence intensity before the start of test solution application. For qualitative evaluation of the drug action, increases in $\Delta F$ greater than 0.1 were considered to be relevant changes. This criterion was chosen as mean $+\mathrm{SD}$ of $\Delta F$ induced by application of control ECS containing $1 \%$ DMSO, $20 \mu \mathrm{M}$ glycine, $2 \mathrm{mM} \mathrm{Ca}^{2+}$, and no added $\mathrm{Mg}^{2+}$ in GFP/GluN1/GluN2Btransfected cultures and assessed in GFP-positive HEK293 cells ( $\triangle F=0.06 \pm 0.04 ; n=27$ ) (see below).

The drugs were purchased from Sigma (St. Louis, MO) or Tocris Cookson Ltd. (Avonmouth, UK). The neurosteroid PS was synthesized by H.C. according to a previously published method (Arnostova et al. 1992) and their purity ( $>98 \%$ ) was repeatedly tested by nuclear magnetic resonance, high performance liquid chromatography, thin-layer chromatography, and elemental analyses. Results are presented as mean \pm SEM, with $n$ equal to the number of cells studied; for the statistical comparison of groups, the Mann-Whitney Rank Sum Test was used. $\mathrm{P}<0.05$ was used to determine the significance.

Our recent experiments have shown that the efficacy of PS modulation of NMDARs is affected by intracellular factors (Petrovic et al. 2009). To study the effect of neurosteroids on NMDARs under conditions of relatively intact cells, calcium imaging technique was used. Figure 1A shows the results of experiments in which the effect of PS on glutamate-induced change in 

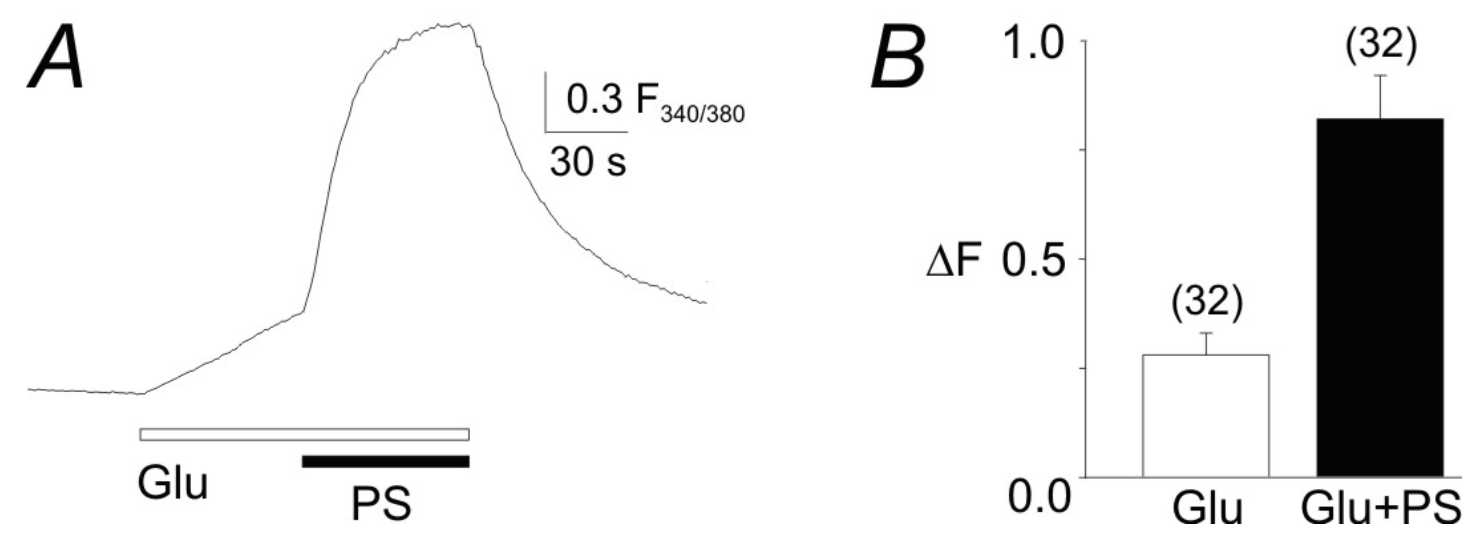

Fig. 1. Agonist-dependent effect of PS. A. A change in the fluorescence ratio $\left(F_{340 / 380}\right)$ in a GFP-positive HEK293 cell in a culture transfected by GFP, GluN1, and GluN2B. The response was induced by $0.3 \mu \mathrm{M}$ glutamate (the duration is indicated by open bar) and its co-application with $300 \mu \mathrm{M}$ PS (indicated by filled bar). Glutamate and the neurosteroid were applied in the ECS containing $1 \%$ DMSO, $20 \mu \mathrm{M}$ glycine, $2 \mathrm{mM} \mathrm{Ca}^{2+}$, and no added $\mathrm{Mg}^{2+}$. B. Bar graph summarizes the relative changes in the fluorescence $(\Delta \mathrm{F})$ induced by $0.3 \mu \mathrm{M}$ glutamate (Glu) and its co-application with $300 \mu \mathrm{M}$ PS (Glu + PS). The relative changes in the fluorescence induced by glutamate application were calculated from $\Delta F=F_{G L U}-F_{0}$, where $F_{0}$ is the fluorescence intensity ratio at 340 and $380 \mathrm{~nm}$ before the start of test solution application and $\mathrm{F}_{\mathrm{GLU}}$ is the fluorescence ratio at the end of glutamate application. In the case of glutamate and PS, co-application the fluorescence was calculated from $\Delta F=F_{(G L U+P S)}-F_{0}$, where $F_{(G L U+P S)}$ is the fluorescence ratio at the end of glutamate and PS co-application. Error bars represent mean \pm SEM, and the number of cells studied is indicated in parentheses. There is a statistically significant difference between $\Delta \mathrm{F}$ induced by glutamate and its co-application with PS (Mann-Whitney: $\mathrm{P}=0.002$ ).

fluorescence $(\Delta F)$ was assessed. In the continuous presence of $20 \mu \mathrm{M}$ glycine, application of $0.3 \mu \mathrm{M}$ glutamate in ECS (with no added $\mathrm{Mg}^{2+}$ ) for $60 \mathrm{~s}$ induced a change in fluorescence $(\Delta F=0.28 \pm 0.05 ; n=32)$ (Fig. 1A,B) in GFP/GluN1/GluN2B-transfected cultures of HEK293 cells. This response was significantly enhanced when PS $(300 \mu \mathrm{M})$ was co-applied with glutamate for an additional $60 \mathrm{~s}(\Delta F=0.82 \pm 0.1 \quad(n=32)$; Mann-Whitney: $\mathrm{P}=0.002)$. Surprisingly, in control experiments the application of PS $(300 \mu \mathrm{M})$ in the absence of glutamate also induced a change in the fluorescence of GFP-positive HEK-293 cells (Fig. 2A,C). The effect of PS on agonist-induced NMDAR responses is consistent with the effect of this steroid on current responses recorded from both native and recombinant receptors using patch clamp technique (Bowlby 1993, Weaver et al. 1998, Horak et al. 2004); however, [ $\left.\mathrm{Ca}^{2+}\right]_{\mathrm{i}}$ rise induced by PS application in the absence of added NMDAR agonist has not yet been characterized.

Before characterizing the effect of PS in detail, we performed a series of control experiments. These indicated that a majority (65-81\%, depending on the transfection batch) of GFP-positive HEK293 cells in GFP/GluN1/GluN2B-transfected cultures were sensitive to $1 \mu \mathrm{M}$ glutamate applied in ECS containing no added $\mathrm{Mg}^{2+}$, while only a small fraction $(<7 \%)$ of GFPnegative HEK293 cells in GFP/GluN1/GluN2Btransfected cultures and HEK293 cells in non-transfected cultures responded to glutamate by a change in $\Delta F$. This agrees well with the results of our electrophysiological experiments showing a high variability in the amplitude of glutamate-induced responses, with a small fraction of GFP-positive HEK293 cells not responding even to a high glutamate concentration. To reduce the variability in the data, we analysed the PS responses in GFP-positive HEK293 cells in GFP/GluN1/GluN2-transfected cultures that were also sensitive to $1 \mu \mathrm{M}$ glutamate (GG-cells). Glutamate non-responding GFP-positive HEK293 cells were excluded from the analysis. Critical $\Delta F\left(\Delta F_{\text {Critical }}\right)$, used to determine glutamate sensitivity, was defined as mean $+\mathrm{SD}$ of the increase in fluorescence $(\Delta F=0.06 \pm 0.04 ; n=27)$ after application of control ECS with no added $\mathrm{Mg}^{2+}$ in the GG-cell in the GFP/GluN1/GluN2B-transfected cultures (see Fig. 2B,F).

On average, $64 \% \quad(n=31)$ of GG-cells in GFP/GluN1/GluN2B transfected cultures (the average number of PS-sensitive cells ranged from $62 \%$ to $73 \%$ of GFP-positive HEK293 cells in 8 different transfections) were sensitive to $300 \mu \mathrm{M}$ PS (PS-induced $\left.\Delta F \geq \Delta F_{\text {Critical }} ; \Delta F_{\text {Critical }}=0.1\right)$ applied in ECS with no added $\mathrm{Mg}^{2+}$; these cells responded on average with a mean increase in fluorescence of $\Delta F=0.6 \pm 0.1 \quad(n=31)$. Following PS application, the cells were allowed to recover (in ECS containing $2 \mathrm{mM} \mathrm{Mg}^{2+}$ ) for $\sim 6 \mathrm{~min}$ and subsequently exposed to $1 \mu \mathrm{M}$ glutamate (Fig. 2C). The glutamate-sensitive cells responded with an increase in fluorescence of $\Delta F=1.3 \pm 0.1$ ( $n=31)$ (Fig. 2F).

An additional analysis was performed on the 

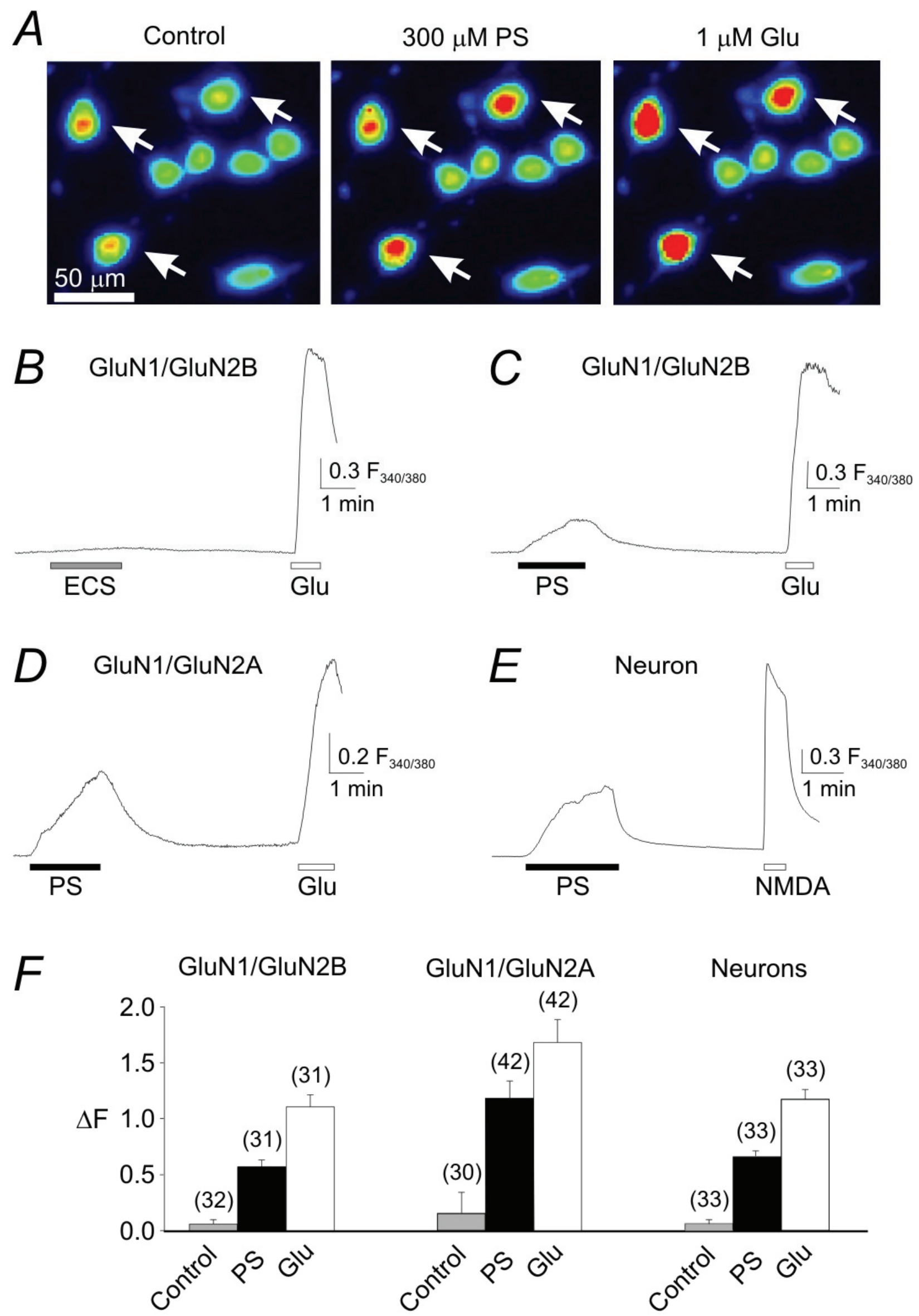
Fig. 2. Agonist-independent effect of PS. A. Changes in the fluorescence ratio at 340 and $380 \mathrm{~nm}$ are indicated in pseudo-colors (fluorescence intensity increases in the order blue-green-yellow-red). The recordings were made in the presence of ECS (no added $\mathrm{Mg}^{2+}$, Control) and ECS supplemented with PS $(300 \mu \mathrm{M})$ and glutamate $(1 \mu \mathrm{M})$. Note that only the GFP-positive cells (indicated by arrows) were glutamate- and PS-sensitive. The figure shows a typical $\mathrm{F}_{340 / 380}$ during application of ECS containing $1 \%$ DMSO, $20 \mu \mathrm{M}$ glycine, $2 \mathrm{mM} \mathrm{Ca}^{2+}$, and no added $\mathrm{Mg}^{2+}$ (ECS) on a GFP-positive HEK293 in culture transfected with GFP/GluN1/GluN2B (B), this solution containing $300 \mu \mathrm{M}$ PS (PS) (C), response to PS in GFP-positive HEK293 in cultures transfected with GFP/GluN1/GluN2A (D), and response to PS in cultured hippocampal neuron (E). The cells sensitive to PS were also sensitive to $1 \mu \mathrm{M}$ glutamate (the duration is indicated by open bar). Records shown in B-E are from different cultures. F. Bar graph summarizing the relative changes in the fluorescence $(\triangle \mathrm{F})$ induced by ECS containing no $\mathrm{Mg}^{2+}$ applied for $2 \mathrm{~min}$ in GFP-positive HEK293 cells in the cultures transfected with GFP/GluN1/GluN2B (Control) and by $300 \mu \mathrm{M}$ PS (PS) applied for 2 min and the maximal response to $1 \mu \mathrm{M}$ glutamate (Glu) in GFPpositive HEK293 cells in cultures transfected by GFP/GluN1/GluN2B (GluN1/GluN2B), GFP/GluN1/GluN2A (GluN1/GluN2A), and cultured hippocampal neurons (Neurons). Error bars represent mean $\pm \mathrm{SEM}$, and the number of cells is indicated in parentheses. There is a significant difference (Mann-Whitney: $\mathrm{P}<0.001$ ) between $\Delta \mathrm{F}$ induced by ECS and PS in GFP-positive HEK293 cells in the cultures transfected by GFP/GluN1/GluN2B, GFP/GluN1/GluN2A, and neurons.

fluorescence intensity of GG-cells insensitive to $300 \mu \mathrm{M}$ PS. The value of the glutamate-induced increase in $\Delta F$ was 2.3-fold lower in PS-insensitive cells than in PSsensitive cells. These data indicate that the differences in the sensitivity of the cells to PS and glutamate likely reflect the differences in the density of NMDAR channels in the cytoplasmatic membranes of HEK293 cells. The recordings in Figure 2D,E indicate that GG-cells in the cultures transfected with GFP/GluN1/GluN2A and cultured hippocampal neurons responded to $300 \mu \mathrm{M}$ PS with a $\Delta F$ that was similar to that observed in GG-cells transfected with GFP/GluN1/GluN2B (Fig. 2E). In the GFP/GluN1/GluN2A-transfected cultures, $69 \%$ of GGcells (29 cells analyzed) were sensitive to $300 \mu \mathrm{M}$ PS and $100 \%$ of neurons ( 69 neurons analyzed) were sensitive to $300 \mu \mathrm{M}$ PS.

We conclude that, in addition to the PS-induced allosteric modulatory effect, this endogenous sulfated steroid can directly gate NMDAR channels. Understanding the molecular mechanism of the steroid modulation of NMDAR channel function is important for understanding the conditions under which endogenous steroids modulate neuronal excitability. In addition, the evaluation of the action of sulfated steroids as probes of receptor behavior may help to assess their potential clinical utility.

\section{Conflict of Interest}

There is no conflict of interest.

\section{Acknowledgements}

This work was supported by the Grant Agency of the Czech Republic (P304/12/G069, P303/12/1464, P303/11/0075), Research Projects RVO:67985823 and RVO:61388963 and the Technology Agency of the Czech Republic (TE01020028: Center for Development of Original Drugs). We thank J. Krusek for helpful discussions and commentary on the project and M. Kuntosova for excellent technical assistance. This publication is supported by the project "BIOCEV Biotechnology and Biomedicine Centre of the Academy of Sciences and Charles University" (CZ.1.05/1.1.00/02.0109), from the European Regional Development Fund.

\section{References}

ABDRACHMANOVA G, CHODOUNSKA H, VYKLICKY L Jr: Effects of steroids on NMDA receptors and excitatory synaptic transmission in neonatal motoneurons in rat spinal cord slices. Eur J Neurosci 14: 495-502, 2001.

ARNOSTOVA LM, POUZAR V, DRASAR P: Synthesis of the sulfates derived from 5 alpha-cholestane- 3 beta, 6 alpha-diol. Steroids 57: 233-235, 1992.

BOWLBY MR: Pregnenolone sulfate potentiation of N-methyl-D-aspartate receptor channels in hippocampal neurons. Mol Pharmacol 43: 813-819, 1993.

CAIS O, SEDLACEK M, HORAK M, DITTERT I, VYKLICKY L Jr: Temperature dependence of NR1/NR2B NMDA receptor channels. Neuroscience 151: 428-438, 2008.

CITRI A, MALENKA RC: Synaptic plasticity: multiple forms, functions, and mechanisms. Neuropsychopharmacology 33: $18-41,2008$.

COLLINGRIDGE GL, OLSEN RW, PETERS J, SPEDDING M: A nomenclature for ligand-gated ion channels. Neuropharmacology 56: 2-5, 2009. 
HOLLMANN M, BOULTER J, MARON C, BEASLEY L, SULLIVAN J, PECHT G, HEINEMANN S: Zinc potentiates agonist-induced currents at certain splice variants of the NMDA receptor. Neuron 10: 943-954, 1993.

HORAK M, VLCEK K, PETROVIC M, CHODOUNSKA H, VYKLICKY L Jr: Molecular mechanism of pregnenolone sulfate action at NR1/NR2B receptors. J Neurosci 24: 10318-10325, 2004.

HOSIE AM, WILKINS ME, SMART TG: Neurosteroid binding sites on GABA(A) receptors. Pharmacol Ther 116: 719, 2007.

ISHII T, MORIYOSHI K, SUGIHARA H, SAKURADA K, KADOTANI H, YOKOI M, AKAZAWA C, SHIGEMOTO R, MIZUNO N, MASU M, NAKANISHI S: Molecular characterization of the family of the Nmethyl-D-aspartate receptor subunits. J Biol Chem 268: 2836-2843, 1993.

MAJEWSKA MD, SCHWARTZ RD: Pregnenolone-sulfate: an endogenous antagonist of the gamma-aminobutyric acid receptor complex in brain? Brain Res 404: 355-360, 1987.

MAJEWSKA MD, HARRISON NL, SCHWARTZ RD, BARKER JL, PAUL SM: Steroid hormone metabolites are barbiturate-like modulators of the GABA receptor. Science 232: 1004-1007, 1986.

MONYER H, SPRENGEL R, SCHOEPFER R, HERB A, HIGUCHI M, LOMELI H, BURNASHEV N, SAKMANN B, SEEBURG PH: Heteromeric NMDA receptors: molecular and functional distinction of subtypes. Science 256: 1217-1221, 1992.

PARK-CHUNG M, WU FS, FARB DH: 3 alpha-hydroxy-5 beta-pregnan-20-one sulfate: a negative modulator of the NMDA-induced current in cultured neurons. Mol Pharmacol 46: 146-150, 1994.

PETROVIC M, SEDLACEK M, HORAK M, CHODOUNSKA H, VYKLICKY L Jr: 20-oxo-5beta-pregnan-3alpha-yl sulfate is a use-dependent NMDA receptor inhibitor. J Neurosci 25: 8439-8450, 2005.

PETROVIC M, SEDLACEK M, CAIS O, HORAK M, CHODOUNSKA H, VYKLICKY L Jr: Pregnenolone sulfate modulation of N-methyl-D-aspartate receptors is phosphorylation dependent. Neuroscience 160: 616-628, 2009.

STELL BM, BRICKLEY SG, TANG CY, FARRANT M, MODY I: Neuroactive steroids reduce neuronal excitability by selectively enhancing tonic inhibition mediated by delta subunit-containing $\mathrm{GABA}_{\mathrm{A}}$ receptors. Proc Natl Acad Sci U S A 100: 14439-14444, 2003.

WANG M, HE Y, EISENMAN LN, FIELDS C, ZENG CM, MATHEWS J, BENZ A, FU T, ZORUMSKI E, STEINBACH JH, COVEY DF, ZORUMSKI CF, MENNERICK S: 3beta-hydroxypregnane steroids are pregnenolone sulfate-like GABA(A) receptor antagonists. J Neurosci 22: 3366-3375, 2002.

WEAVER CE Jr, WU FS, GIBBS TT, FARB DH: Pregnenolone sulfate exacerbates NMDA-induced death of hippocampal neurons. Brain Res 803: 129-136, 1998.

WU FS, GIBBS TT, FARB DH: Pregnenolone sulfate: a positive allosteric modulator at the N-methyl-D-aspartate receptor. Mol Pharmacol 40: 333-336, 1991.

ZHU WJ, VICINI S: Neurosteroid prolongs GABA $_{\mathrm{A}}$ channel deactivation by altering kinetics of desensitized states. J Neurosci 17: 4022-4031, 1997. 